\title{
Metabolomic profiling in blood from umbilical cords of low birth weight newborns
}

\author{
Carmen Ivorra ${ }^{1,2}$, Consuelo García-Vicent ${ }^{1}$, Felipe Javier Chaves $^{3,4}$, Daniel Monleón ${ }^{5}$, José Manuel Morales ${ }^{6}$ and \\ Empar Lurbe ${ }^{1,2,7^{*}}$
}

\begin{abstract}
Background: Low birth weight has been linked to an increased risk to develop obesity, type 2 diabetes, and hypertension in adult life, although the mechanisms underlying the association are not well understood. The objective was to determine whether the metabolomic profile of plasma from umbilical cord differs between low and normal birth weight newborns.
\end{abstract}

Methods: Fifty healthy pregnant women and their infants were selected. The eligibility criteria were being born at term and having a normal pregnancy. Pairs were grouped according to their birth weight: low birth weight (LBW, birth weight $<10^{\text {th }}$ percentile, $n=20$ ) and control (control, birth weight between the $75^{\text {th }}-90^{\text {th }}$ percentiles, $n=30$ ). Nuclear Magnetic Resonance (NMR) was used to generate metabolic fingerprints of umbilical cord plasma samples. Simultaneously, the metabolomic profiles of the mothers were analysed. The resulting data were subjected to chemometric, principal component and partial least squares discriminant analyses.

Results: Umbilical cord plasma from LBW and control newborns displayed a clearly differentiated metabolic profile. Seven metabolites were identified that discriminate the LBW from the control group. LBW newborns had lower levels of choline, proline, glutamine, alanine and glucose than did the control newborns, while plasma levels of phenylalanine and citrulline were higher in LBW newborns $(p<0.05)$. No significant differences were found between the two groups of mothers.

Conclusions: Low birth weight newborns display a differential metabolomic profile than those of normal birth weight, a finding not present in the mothers. The meaning and the potential utility of the findings as biomarkers of risk need to be addressed in future studies.

Keywords: Low birth weight, Umbilical cord, Metabolomics, Amino acids, Fetal factors

\section{Background}

The concept of the fetal origin of adult disease suggests that early life conditions can "program" the fetus for a spectrum of adverse health outcomes in adulthood [1,2]. Low birth weight babies (LBW), typically defined as birth weight below the $10^{\text {th }}$ percentile according to gestational age [3], have an increased risk of rapid postnatal weight gain, later obesity, and diseases in adulthood such as type 2 diabetes, hypertension and ischemic heart disease [4-6]. Therefore, cardiovascular risk is determined

\footnotetext{
* Correspondence: empar.lurbe@uv.es

${ }^{1}$ Cardiovascular Risk Unit, Consorcio, Hospital General, University of Valencia,

Av. Tres Cruces s/n, Valencia 46014, Spain

${ }^{2}$ CIBER Fisiopatología Obesidad y Nutrición (CB06/03), Instituto de Salud

Carlos III, Madrid, Spain

Full list of author information is available at the end of the article
}

not only by conventional risk factors of importance in adult life, but also by early life programming based on intrauterine fetal growth [7].

The mechanistic pathways underlying the relationship between fetal growth restriction and cardiovascular risk are poorly understood [8]. Although the cause of this relationship is unknown, several hypotheses have been proposed: involvement of the kidney (reduction of nephron number, activation of the renin-angiotensin system, an increase in renal sympathetic nerve activity), the neuroendocrine system (up-regulation of the hypothalamicpituitary-adrenal axis, altered adaptation to stress), and early abnormalities in the vasculature tree $[9,10]$.

A previous study has demonstrated that endothelial cells from umbilical cord artery derived from individuals 
of LBW exhibit a different phenotype when compared to that from individuals of higher birth weight [11]. This observation could imply that it is possible to identify functional and/or structural differences at birth which can contribute to providing better information with respect to the risk of developing disease later in life. A further approach to studying differences between low and normal birth weight newborns is to assess their metabolomic profiles.

Metabolomics, the study of small-molecule metabolites, is a discipline that focuses on the measurement of the relative concentrations of endogenous small molecules in biofluids. This technology may be useful for understanding metabolic imbalances and for diagnosing human diseases. Recently, studies using metabolomics have been used to identify a discriminatory metabolite profile in a number of areas: preeclampsia in early pregnancy [12], diabetes [13], obesity [14], [15], risk for preterm delivery [16]. It has been suggested they predict the presence and severity of cardiovascular disease [17-20]. There are no data about its use to identify a metabolite profile in umbilical cord from LBW children. The objective of the present study was to analyse the metabolomic profile at birth in newborns with LBW, and to compare it with those from normal birth weight children. Simultaneously, the metabolomic profiles of their mothers were analysed. The identification of deregulated metabolites would potentially give clues for better understanding the abnormalities associated with LBW.

\section{Methods}

\section{Subjects and sample collection}

Newborns were included if born at term (gestational age $\geq 37$ weeks), after uncomplicated pregnancies ascertained according to the Ballard method [21], and by normal delivery or Cesarean section in the absence of perinatal illness at the Hospital General Universitario of Valencia, Spain. All the mothers were healthy and had no cardiovascular risk factors. Fifty newborns and their mothers of European origin were selected to participate in the study. Umbilical cord blood samples were obtained from the clamped umbilical cord immediately after delivery. The samples of their mothers were drawn at 2-4 h after delivery in non-fasting conditions, but with at least 8 hours having passed since the last meal and blood sampling. Two groups of newborns were created according to birth weight: lower than the $10^{\text {th }}$ percentile (lower than $2.5 \mathrm{~kg}$; LBW group, $\mathrm{n}=20$ ) or appropriate birth weight for gestational age (control group, birth weight between the $75^{\text {th }}-90^{\text {th }}$ percentiles, $\mathrm{n}=30$ ) [22]. Parents gave their consent for the study after they were given informed in writing of the objectives of the research project and of the samples that would be taken. The study was approved by the hospital's review board and was carried out in accordance with the Declaration of Helsinki. Both the samples (plasma from umbilical cord of the newborns and plasma from peripheral veins from the mothers), as well as the collected data, were stored according to the directives dictated by the law of Biomedical Investigation of 2007 (Law 14/2007) and all applicable rules.

\section{Metabolomic profile \\ Storage, preparation and ${ }^{1} \mathrm{H}$ Nuclear magnetic resonance spectroscopic analysis of blood plasma}

Umbilical venous cord blood and maternal peripheral venous blood were collected in EDTA-tubes, centrifuged to yield plasma, stored at $-80{ }^{\circ} \mathrm{C}$ and thawed before use. For Nuclear Magnetic Resonance (NMR) analysis, $500 \mu \mathrm{l}$ of plasma were mixed with $50 \mu \mathrm{l}$ of $\mathrm{D}_{2} \mathrm{O}$ (as a field lock). A total of $500 \mu \mathrm{l}$ of the mixture of each sample was then individually transferred into a $5 \mathrm{~mm}$ high quality NMR tube. All ${ }^{1} \mathrm{H}$ NMR spectra were acquired using a standard one-dimensional pulse sequence with water suppression (Bruker Avance 600 spectrometer operating at $600.13 \mathrm{MHz}$ with a $1 \mathrm{~mm}^{1} \mathrm{H} /{ }^{13} \mathrm{C} /{ }^{15} \mathrm{~N}$ TXI probe). A total of 256 FIDs (free induction decay) were collected into $64 \mathrm{k}$ data points with a spectral width of $14 \mathrm{ppm}$ and a recycle delay (RD) of $1 \mathrm{~s}$. The water signal was saturated with weak irradiation during the recycle delay. Before Fourier transformation, the free induction decay was multiplied by a $0.3 \mathrm{~Hz}$ exponential line broadening.

Spectral chemical shift referencing on the Alanine $\mathrm{CH}_{3}$ doublet signal at $1.475 \mathrm{ppm}$ was performed in all spectra. Resonances in these spectral regions were assigned using the literature [23] and two-dimensional spectra were selected (2D NMR, especially for long chain metabolites). Spectral regions between 0.5 and 4.5 ppm and between 5.5 and $9.5 \mathrm{ppm}$ were binned in segments of $0.01 \mathrm{ppm}$ width $(6 \mathrm{~Hz})$ for multivariate analysis. Data binning in NMR spectra for multivariate analysis is a common pre-processing practice [24,25], which, although it may decrease the effect of minor observations, allows for the detection of relevant regions, decreases the risk of model overfitting and artificially increases the signal to noise-ratio. Data binning reduces the impact of read noise on the processed data at the cost of a lower resolution. We used binning only for the pattern recognition. There are two benefits associated with the use of pattern recognition approaches in the binning of spectral data. First, the signal-to-noise ratio increases. Second, there is a reduction in the possibility of overfitting. Once the bucket with the relevant peaks in each spectra were identified, they were quantified. Therefore, the values reported are quantified peaks by spectral integration. The binned data was normalised to the total spectral area. Thus, the individual peak intensities were normalized to total metabolite content for 
better a comparison between samples. Spectral regions belonging to the EDTA resonances (2.52 to $2.57 \mathrm{ppm}$ and 3.06 to3.17 ppm) were removed from the spectra for subsequent analysis. The available spectral databases and 2D NMR experiments were used to aid in structural identification of the relevant metabolites. All spectra were processed using Topspin 1.3 (Bruker Biospin GmbH, Germany) and transferred to MATLAB ${ }^{\circledR}$ (MathWorks Inc, 2006) using in-house scripts for data analysis. Signals belonging to selected metabolites were integrated and quantified using semi-automated inhouse MATLAB peak-fitting routines. These fitting routines were based on Levenburg-Marquard optimization procedures. The target function for the optimization included experimental spectra measured for standard solutions of selected metabolites with complex multiplet patterns and theoretically generated Lorentzian-shape signals for those metabolites with simpler spectral patterns. One way analysis of variance (ANOVA) was used for the determination of statistical significance between group means of the corresponding integrals.

\section{Multivariate analysis of nuclear magnetic resonance spectra}

In the present study, binned spectral regions for blood plasma were mean-centered chemometric analyses. Relevant bins were identified in our chemometric models. The relevant spectral regions within these bins were identified and quantified by spectral integration. Chemometric and statistical analyses were performed using inhouse MATLAB scripts and the PLS Toolbox (Eigenvector Research, Inc.). Principal Component Analysis (PCA) and Projection to Latent Structures for Discriminant Analysis (PLS-DA) were applied to NMR spectra data sets. PCA is able to find low dimensional embeddings of multivariate data in a way that optimally preserves the structure of the data. The PCA technique transforms the variables of a data set into a smaller number of new latent variables called principal components (PCs) which are uncorrelated to each other and account for decreasing proportions of the total variance of the original variables. Each new PC is a linear combination of the original variation so that a compact description of the variation within the data set is generated. Observations are assigned scores according to the variation measured by the principal component $\mathrm{X}$, with those having similar scores clustering together. Where PCA proved inadequate to define clustering, a supervised approach was used.

PLS-DA is a classification technique that combines the properties of Partial Least Squares regression with the discrimination power of discriminant analysis [26]. The main advantage of PLS-DA models is that the main sources of variability in the data are modeled by the so- called latent variables (LVs) and, consequently, in their associated scores and loadings. This allows for the visualization and understanding of different patterns and relations in the data. PLS-DA is a supervised extension of PCA that is used to distinguish two or more classes by searching for variables (X matrix) that are correlated to class membership ( $\mathrm{Y}$ matrix). In this approach, the axes are calculated to maximize class separation and can be used to examine separation that would otherwise be across three or more principal components [26]. In order to discriminate between samples associated with low weight and normal weight at birth, a PLS-DA model was devised. The PLS-DA model discriminating between controls and LBW was cross-validated by technical replication of the whole process on 25 random data splits. To validate the model, important quality parameters were calculated: $R^{2} X, R^{2} Y, Q^{2}$ and RMSP. $R^{2} X$ and $R^{2} Y$ describe the variation in the $\mathrm{X}$ and $\mathrm{Y}$ variables, respectively. $Q^{2}$ describes predictability. RMSP (Root mean squared error of prediction) gives a direct indication of the error in the predicted value.

\section{Statistical analysis}

Values were expressed as mean \pm SD for each study group. The differences in the mean values of anthropometric parameters between the groups were assessed by analysis of variance (ANOVA) adjusted by sex. The normality of the data was verified using the KolmogorovSmirnov test. Choline, glutamine, alanine and glycogen in the control group do not have a normal distribution, and a Kruskal-Wallis test was used for these variables. An outlier analysis was performed, and those samples deviating from the mean by more than 2.5 times the standard deviation were excluded. A significant difference was considered present if $\mathrm{p}<0.05$. Pearson's correlation coefficients were used to examine the relations between variables. Statistical analyses were performed using SPSS 15.0. (SPSS Inc, Chicago, Illinois, USA) and GraphPad Statmate 5.0 (GraphPad Software, La Jolla, California, USA) software graphs.

\section{Results}

\section{Clinical characteristics of mothers and newborns}

The general characteristics of mothers and their newborns are shown in Table 1 . No differences were observed in maternal age, maternal BMI, pregnancy weight gain or type of delivery between the two groups. Although no significant differences were observed in heart rate and diastolic blood pressure between newborns groups (Table 1), differences appeared in sex, height, head circumference and blood pressure. As expected, the LBW group had systolic values significantly lower than those for the control birth weight group [10]. All comparisons between newborns groups 
were adjusted by sex, and no changes were noted when comparing boys with girls.

\section{Metabolomic profile in umbilical cord blood in low birth weight and control newborns}

The standard 1D NMR spectrum is shown in Figure 1A. PCA and PLS-DA scatter plot were performed on the pre-processed NMR spectra comparing plasma from LBW versus control newborns and were used to identify metabolite clusters. Although an unsupervised analysis by PCA does not show differences between groups, Figure $1 \mathrm{~B}$, a supervised classification method (PLS-DA, 3 Latent Variables, see Additional file 1: Figure S1) provides a differential global metabolic profile, Figure $1 \mathrm{C}$. The model had a $R^{2} X$ (cumulative) of 0.623 , a $R^{2} Y$ (cumulative) of 0.871 , a $\mathrm{Q}^{2}$ (cumulative) of $0.523\left(\mathrm{a} \mathrm{Q}^{2}\right.$ value superior to 0.5 is generally considered to be a good predictor) and a RMSP of 0.417 (medium predictive capacity). Spectral regions and peaks with the highest contribution to the loadings plot from this model were further quantified and analysed. Many metabolites may contribute to these loading plots and to the separation between classes. A total of thirty-four metabolites were tested in fifty-eight spectral regions, and the differences were evaluated by the T-Student test with the KruskalWallis correction. However, only those that differed with $\mathrm{p}<0.05$ were taken into consideration.

Of the 34 metabolic regions studied, 17 compounds were quantified according to the loadings of the multivariate analysis. Among the 17 metabolites, significant differences were observed for seven (proline, free choline, glutamine, alanine, glucose, phenylalanine and citrulline) between the LBW and the control group, while no differences were observed in the other seven (spectral region containing lipoproteins peaks, in carbohydrates and glycogen fragments, in ketone bodies like acetoacetate and hydroxybutyrate, in total lipids and in fatty acids both saturated and unsaturated) (data not shown).

Table 2 shows median values \pm SD for arbitrary units of intensity $\left(\mathrm{AUIx} 10^{-3}\right)$ from identified metabolites, and Figure 2 provides the individual levels of 7 metabolites that display significant level differences between the two groups. In the LBW group, all metabolites have a normal distribution, and samples are more homogeneous than in the control group. In the control group, choline, glutamine and alanine do not have a normal distribution. An outlier analysis was carried out, and two subjects were excluded from the control group.

Five metabolites (proline, choline, glutamine, alanine and glucose) were reduced in the LBW group as compared to those for the controls. In the LBW group, proline values were $38.1 \%$ less $(21.74 \pm 9.80$ AUI vs $13.00 \pm$ 7.5 AUI; p-value $=0.002$ ) while free choline was $31.4 \%$ less $(3.76 \pm 0.17 \mathrm{AU}$ vs $2.58 \pm 0.07 \mathrm{AU}$; p-value $=0.005)$. Glutamine (3.68 \pm 0.17 vs $2.59 \pm 0.07$; p-value $=0.004)$, alanine $(9.49 \pm 4.1$ vs $7.00 \pm 2.2$; $\mathrm{p}$-value $=0.008)$ and glucose levels $(2.15 \pm 0.98$ vs $1.59 \pm 0.50$; p-value $=$ 0.023 ) were significantly lower in LBW newborns as well. In addition, LBW newborns exhibited a $15.7 \%$ increase in values of phenylalanine $(1.07 \pm 0.03$ vs $1.27 \pm$ $0.03 \mathrm{p}$-value $=0.018)$ and a $20.2 \%$ increase in values of citrulline $(0.67 \pm 0.02$ vs $0.84 \pm 0.002 ; \mathrm{p}$-value $=0.008)$. No difference in profiles between sexes was observed.

Table 1 Anthropometric and clinical characteristics of mothers and newborns grouped by birth weight

\begin{tabular}{|c|c|c|c|}
\hline & Control $(n=30)$ & LBW $(n=20)$ & p-value \\
\hline \multicolumn{4}{|l|}{ Maternal Characteristics } \\
\hline Maternal age (years) & $30.22 \pm 5.65$ & $30.50 \pm 6.10$ & NS \\
\hline Pregnancy weight gain (g) & $12581 \pm 428$ & $11025 \pm 301$ & NS \\
\hline Delivery (vaginal/Cesarean section) & $21 / 9(70 \%)$ & $12 / 8(60 \%)$ & NS \\
\hline Maternal Body Mass Index & $24.0 \pm 3.1$ & $22.8 \pm 2.1$ & NS \\
\hline \multicolumn{4}{|l|}{ Newborns Characteristics } \\
\hline Gestational age at delivery (weeks) & $38.95 \pm 0.90$ & $37.64 \pm 1.50$ & $p<0.05$ \\
\hline Sex (male/female) & 20/10 (66.7\%) & 5/15 (33.3\%) & $p<0.01$ \\
\hline Birth weight (g) & $3756 \pm 148$ & $2371 \pm 177$ & $p<0.0001$ \\
\hline Height (cm) & $50.46 \pm 1.45$ & $45.55 \pm 1.14$ & $p<0.0001$ \\
\hline Head circumference (cm) & $34.70 \pm 1.00$ & $32.10 \pm 1.80$ & $p<0.0001$ \\
\hline Systolic blood pressure (mmHg) & $73.88 \pm 13.20$ & $65.15 \pm 11.50$ & $p<0.05$ \\
\hline Diastolic blood pressure (mmHg) & $44.20 \pm 11.22$ & $40.70 \pm 8.70$ & NS \\
\hline Heart rate (bpm) & $130.14 \pm 16.30$ & $128.33 \pm 17.90$ & NS \\
\hline
\end{tabular}

The values are expressed as mean \pm SD; $p$-value, statistical significance of the differences among groups; NS, Non-significant; LBW, low birth weight. 


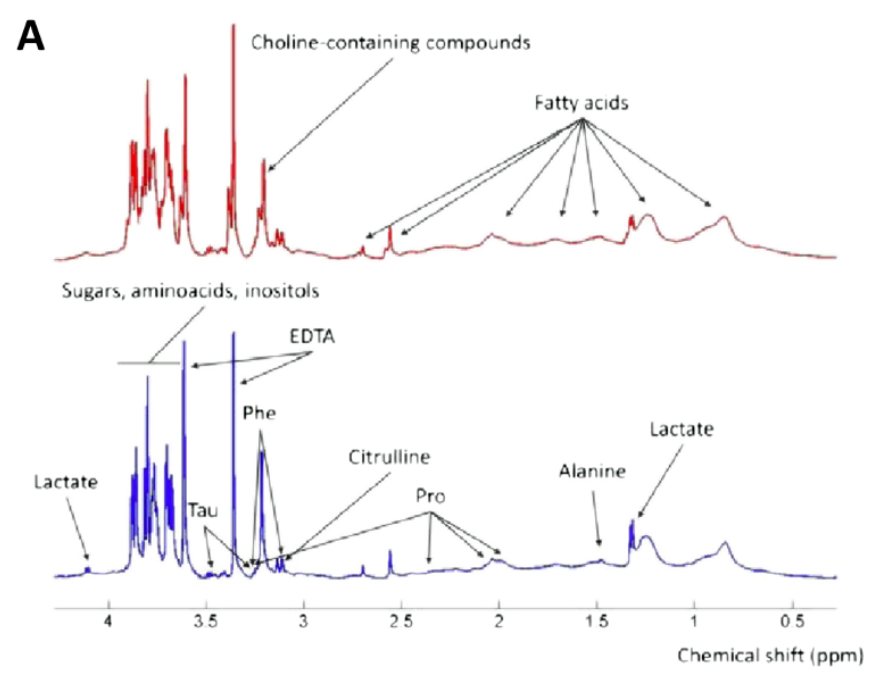

B

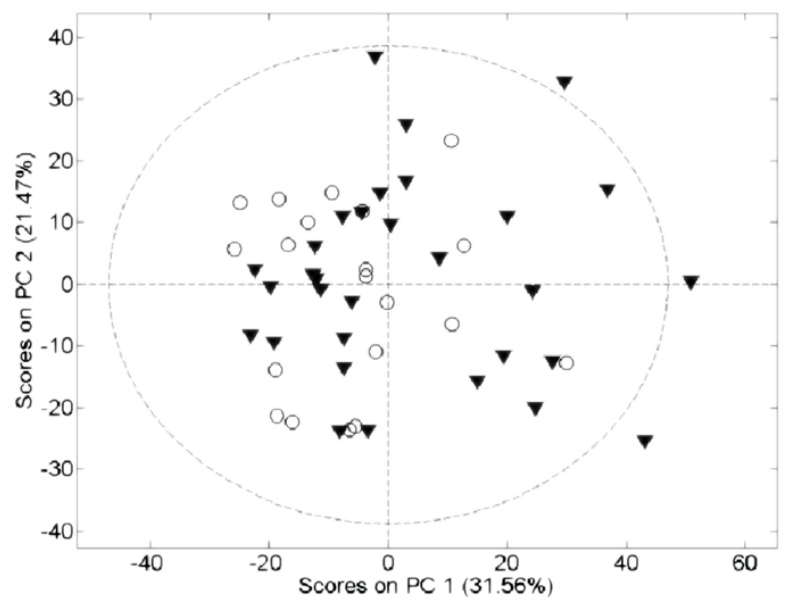

C

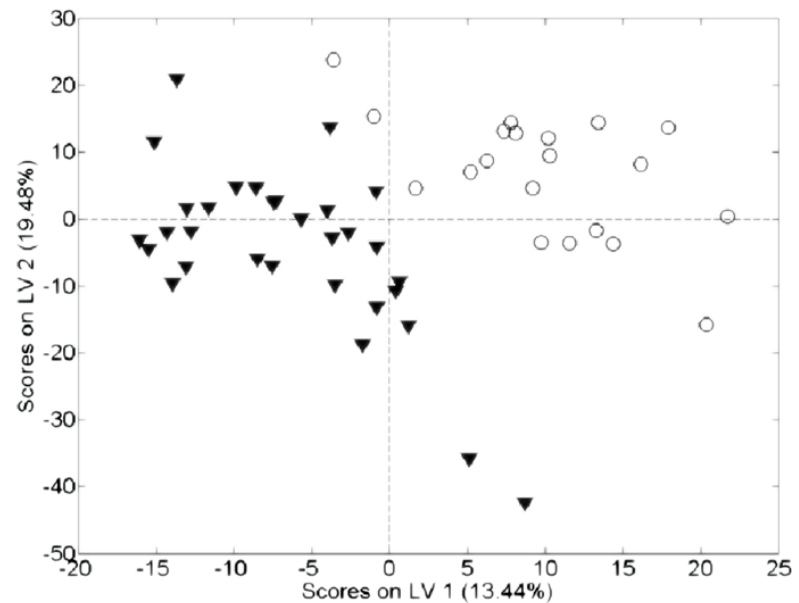

Figure 1 Umbilical cord blood profile. Superposed ${ }^{1}$ H NMR spectra for the spectra of umbilical cord blood plasma (Panel A), Principal Component Analysis scores plot (PCA, panel B), and Projection to Latent Structures for Discriminant Analysis scores plot (PLS-DA, panel C) showing the global metabolic differences between low birth weight (open circles, blue spectra) and control birth weight (black triangles and red spectra) newborns. Although an unsupervised analysis by PCA does not show differences between groups, a supervised classification method (PLS-DA) provides a differential global metabolic profile. The cross-validated error percentage of the model for the classification of low weight at birth samples is $8 \%$. Metabolites exhibiting largest differences between groups have been listed in Table 2 .

Maternal metabolic profile in venous peripheral blood Nuclear Magnetic Resonance data from mothers were processed to give the initial PCA plot after a partial least squares-discriminate analysis (Figure 3, PLS-DA, 3 Latent Variables, see Additional file 1: Figure S2). The PLS-DA model had a $\mathrm{R}^{2} \mathrm{X}$ (cumulative) of 0.512 , a $\mathrm{R}^{2} \mathrm{Y}$ (cumulative) of 0.611 , a $\mathrm{Q}^{2}$ (cumulative) of $0.502\left(\mathrm{a} \mathrm{Q}^{2}\right.$ value superior to 0.5 is generally considered to be a good predictor) and a RMSP of 0.282 (low predictive capacity). The loadings plot showed 14 spectral regions with high relative weight belonging to 10 metabolites. Table 2 shows median values \pm SD for arbitrary units of intensity
$\left(\mathrm{AUIx} 10^{-3}\right)$ from the identified metabolites. From a total of 10 metabolites, 6 were related to the amino acid group (proline, phenylalanine, alanine, glutamine, citrulline and free choline), 2 were related to the carbohydrate group (glucose and glycogen fragments), and 2 to the lipid group (spectral region containing large LDL + VLDL lipoproteins peaks and polyunsaturated fatty acids (PUFAs)). The results of the metabolomic profiling in maternal blood showed no significant differences between the two groups of mothers at either the PLS-DA score plot level and at the individual identified metabolite level (Table 2, p-value M-C vs M-LBW). 
Table 2 List of identified metabolites in umbilical cord plasma and in maternal peripheral blood

\begin{tabular}{|c|c|c|c|c|c|c|c|c|c|}
\hline & \multicolumn{2}{|l|}{ NEWBORNS } & \multirow{2}{*}{$\frac{p \text {-value }}{\text { C vs LBW }}$} & \multicolumn{2}{|l|}{ MOTHERS } & \multirow{2}{*}{$\begin{array}{l}\frac{\text { p-value }}{\text { M-C vs }} \\
\text { M-LBW }\end{array}$} & \multicolumn{2}{|c|}{ Feto-maternal ratio } & \multirow{2}{*}{$\begin{array}{l}\text { p-value } \\
\text { Control vs } \\
\text { LBW }\end{array}$} \\
\hline & $\begin{array}{l}\text { Control } \\
(\mathrm{n}=30)\end{array}$ & $\begin{array}{l}\text { LBW } \\
(n=20)\end{array}$ & & $\begin{array}{l}\text { M-Control } \\
(\mathrm{n}=30)\end{array}$ & $\begin{array}{l}\text { M-LBW } \\
(\mathrm{n}=20)\end{array}$ & & Control & LBW & \\
\hline \multicolumn{10}{|l|}{$\begin{array}{l}\text { Amino Acids } \\
\text { and related }\end{array}$} \\
\hline Proline & $21.74 \pm 9.80$ & $13.00 \pm 7.50$ & 0.002 & $12.22 \pm 0.92$ & $12.10 \pm 0.56$ & NS & $1.73 \pm 0.83$ & $1.26 \pm 0.62$ & 0.023 \\
\hline Free Choline & $3.76 \pm 0.17$ & $2.58 \pm 0.07$ & 0.005 & $5.73 \pm 0.79$ & $5.80 \pm 0.76$ & NS & $0.56 \pm 0.17$ & $0.46 \pm 0.17$ & 0.040 \\
\hline Citrulline & $0.67 \pm 0.02$ & $0.84 \pm 0.02$ & 0.008 & $15.16 \pm 1.09$ & $15.34 \pm 1.22$ & NS & $0.04 \pm 0.01$ & $0.05 \pm 0.02$ & 0.022 \\
\hline Glutamine & $3.68 \pm 0.17$ & $2.59 \pm 0.07$ & 0.004 & $0.85 \pm 0.06$ & $0.85 \pm 0.07$ & NS & $3.68 \pm 1.16$ & $3.07 \pm 0.81$ & 0.024 \\
\hline Alanine & $9.49 \pm 4.10$ & $7.00 \pm 2.20$ & 0.008 & $0.90 \pm 0.03$ & $0.96 \pm 0.20$ & NS & $9.28 \pm 3.29$ & $7.66 \pm 2.64$ & 0.041 \\
\hline Phenylalanine & $1.07 \pm 0.03$ & $1.27 \pm 0.03$ & 0.018 & $9.78 \pm 1.13$ & $9.97 \pm 0.96$ & NS & $0.12 \pm 0.03$ & $0.13 \pm 0.03$ & NS \\
\hline \multicolumn{10}{|l|}{ Carbohydrates } \\
\hline Glucose & $2.15 \pm 0.98$ & $1.59 \pm 0.50$ & 0.023 & $1.12 \pm 0.08$ & $1.10 \pm 0.09$ & NS & $1.65 \pm 0.58$ & $1.43 \pm 0.42$ & NS \\
\hline Glycogen fragments & $2.70 \pm 1.11$ & $2.01 \pm 0.76$ & 0.011 & $2.95 \pm 0.33$ & $2.82 \pm 0.24$ & NS & $0.81 \pm 0.24$ & $0.71 \pm 0.27$ & NS \\
\hline \multicolumn{10}{|l|}{ Lipids } \\
\hline $\begin{array}{l}\mathrm{LDL}+\mathrm{VLDL} \text { enriched } \\
\text { spectral region }\end{array}$ & $7.22 \pm 1.25$ & $7.60 \pm 0.99$ & NS & $5.01 \pm 0.50$ & $4.96 \pm 0.52$ & NS & $1.52 \pm 0.33$ & $1.55 \pm 0.23$ & NS \\
\hline PUFA & N/D & N/D & - & $4.19 \pm 0.49$ & $4.38 \pm 0.38$ & NS & - & - & - \\
\hline
\end{tabular}

The values are expressed as mean \pm SD; $p$-value, statistical significance of the differences among groups; N/D, not detected; LBW, low birth weight. Mean metabolite abundance is indicated by arbitrary units of intensity $\left(\mathrm{AUI} \times 10^{-3}\right)$.

The feto-maternal ratio for carbohydrates (glucose and glycogen fragments), lipids (spectral region containing large LDL + VLDL lipoprotein peaks) and phenylalanine was comparable between the two groups (Table 2, p-value Control vs LBW). In contrast, the feto-maternal ratio for proline, free choline, glutamine and alanine was significantly lower $(\mathrm{p}<0.05)$ in the LBW group, whereas that for citrulline was significantly higher.
Relationship between metabolites and birth weight Pearson correlations were performed for each of the 7 aforementioned metabolites versus birth weight. Out of the 7 metabolites, the analysis identified a significant positive correlation between birth weight and free choline, proline, and glutamine (free choline $r=0.50$, $\mathrm{p}$-value $<0.01$; proline $\mathrm{r}=0.29, \mathrm{p}$-value $<0.05$; glutamine $\mathrm{r}=0.36, \mathrm{p}$-value $<0.01)$. A significant

\section{A}

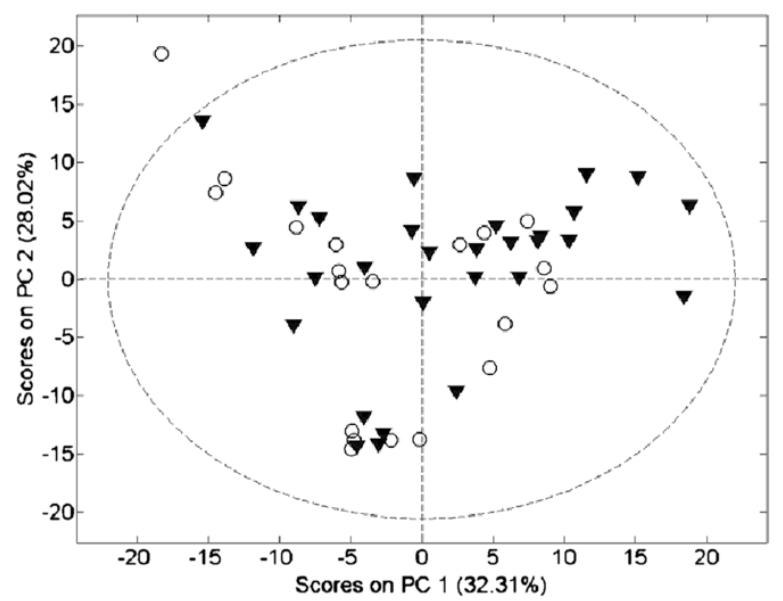

B

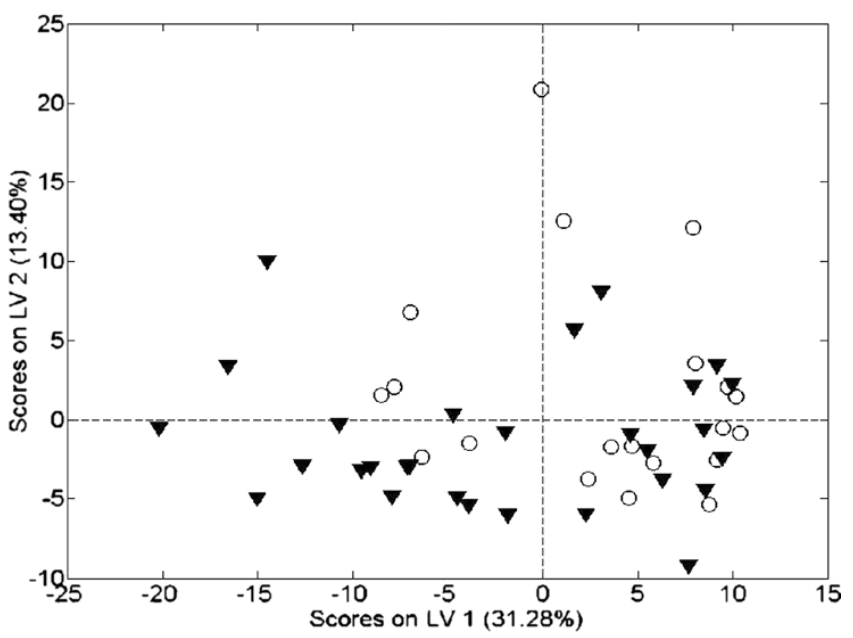

Figure 2 Metabolites distinguishing LBW and control newborns. Glucose, Proline, Glutamine, Choline, and Alanine levels were higher in control newborns. Significantly higher levels of citrulline and phenylalanine were detected in umbilical cord plasma from LBW newborns. Mean metabolite abundance is indicated by line. Each point represents a single newborn. 


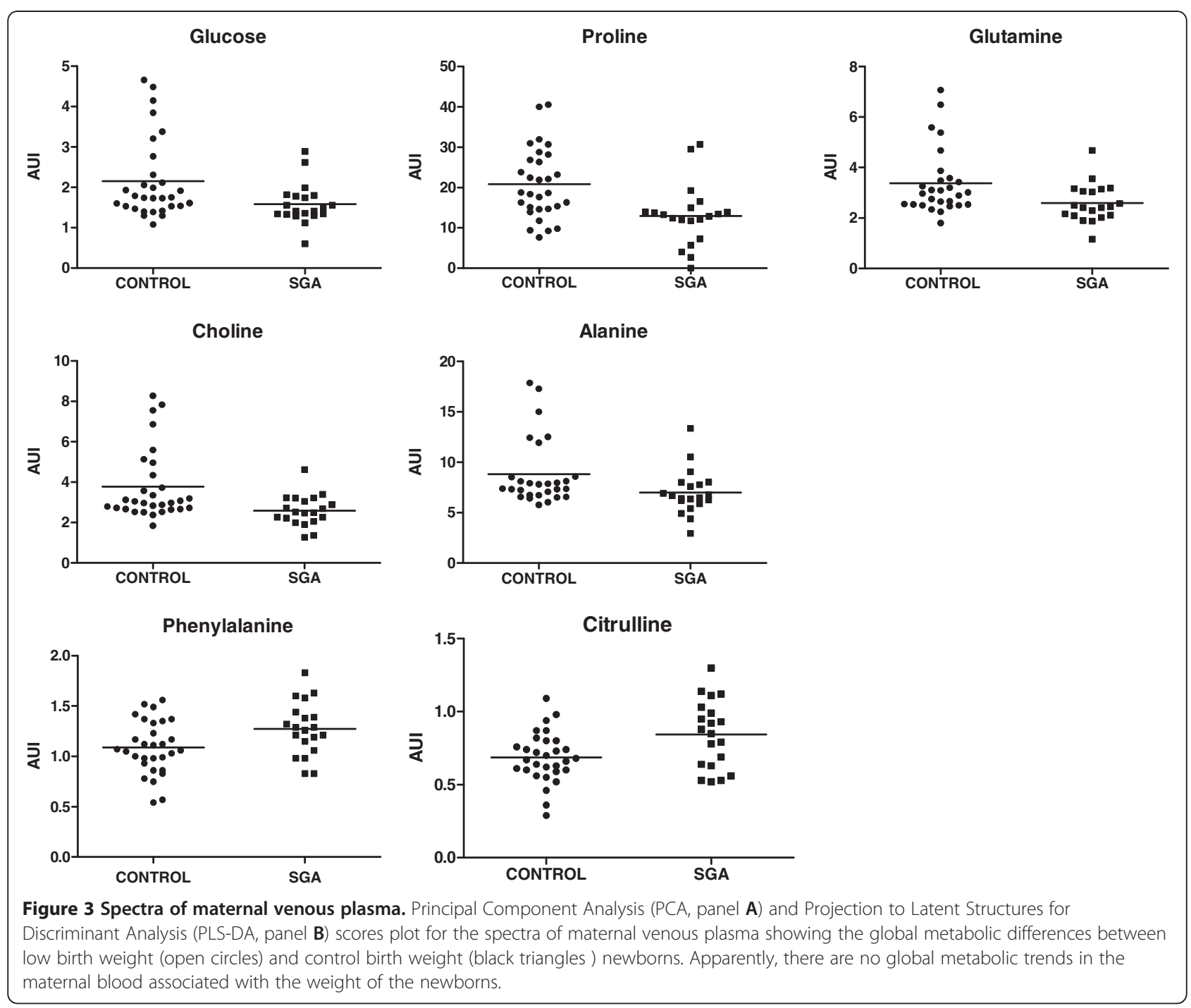

inverse association was found between citrulline and birth weight $(\mathrm{r}=-0.40, \mathrm{p}$-value $<0.01)$ and between phenylalanine and birth weight $(\mathrm{r}=-0.34, \mathrm{p}$-value $<0.05)$; i.e., phenylalanine and citrulline increase as birth weight decreases. No relationships were identified when correlating these metabolites with blood pressure. No significant associations were found between alanine and glucose with birth weight.

\section{Discussion}

The present study is the first to utilize metabolomic analysis in umbilical cord blood samples from LBW children in order to identify metabolites that could be related to the abnormalities associated with the longterm development of the increased cardio-metabolic risk associated with LBW. The metabolomic profile of LBW newborns differed from that observed in a group of newborn controls. Higher values of phenylalanine and citrulline and lower levels of proline, choline, glutamine, alanine and glucose were observed. A significant relationship between some of these metabolites and birth weight was also present. Furthermore, the differences observed in the newborns were not observed in their mothers, all of whom were healthy and had similar weight gains during pregnancy. Although the significance of the observed metabolomic values is not well understood, interesting information can be derived from the present results since some of the observed data have been linked previously to the abnormal metabolic states associated with LBW.

Even though the impact of fetal metabolic programming on adult health is well documented, the underlying mechanisms are poorly understood. Animal models have been used extensively to investigate the mechanism by 
which the early-life environment induces persistent alterations in the metabolism of offspring [27-30]. These studies support the hypothesis that nutritional imbalance during prenatal and early postnatal life can induce long term metabolic changes and increase susceptibility to metabolic diseases in later life [31-33].

The absence of differences found for lipoproteins, carbohydrates, ketone bodies and fatty acids suggests that fatty acid oxidation and glucose metabolism remain unaltered. Changes, however, in the spectral region between 7.27 and $5.36 \mathrm{ppm}$, which has been assigned to glycogen fragments, may suggest alterations in carbohydrate storage. The large molecular size of glycogen makes it very difficult to observe its ${ }^{1} \mathrm{H}$ resonance signals. Longer NMR $\mathrm{T}_{2}$ relaxation times, which suggest smaller molecule sizes, produce the narrow signals observed for that spectral region. Perhaps some macromolecule degradation of glycogen into smaller molecular size fragments is the cause.

In the present study, the mismatch between the mother and the newborn in terms of the metabolomic profile is worth taking into consideration. While a different pattern was observed in the LBW newborns compared to controls, the mothers of both groups had a similar pattern. A trend towards reduced levels of amino acids in the umbilical cord was observed in LBW, something not observed in the mothers. The reason for the discrepancies is not well known, although suboptimal placental transport of amino acids could be involved. Impaired placental amino acid transport is often seen in association with IUGR, yet it is unclear whether the changes in amino acid transport are a cause or a consequence of IUGR [34,35]. Experimental models in rats, however, have suggested a down-regulation of amino acid transporters as a cause rather than a consequence [36]. Consistent with impaired placental amino acid transport as a potential cause of IUGR in humans, umbilical cord blood (but not maternal blood) concentration of most essential amino acids is less in pregnancies with IUGR fetuses [34], [37]. This interesting finding should be addressed in future studies.

In contrast to the reduction of the majority of the amino acid detected are the increased values of phenylalanine, a neutral branched amino acid, in LBW newborn. Higher levels of amino acids, branched and/or aromatic, have been associated with insulin resistance $[38,39]$, and with the risk to develop type 2 diabetes in the Framingham offspring cohort [19]. The potential for amino acids to induce insulin resistance has been recognized for some time [40]. In a low-calorie environment, it is not surprising that large neutral amino acids would promote an anabolic state by inhibiting proteolysis and by directly stimulating protein synthesis [41]. That notwithstanding, the detection of significant spectral regions in the broad protein amide region (between 7.80 and $7.86 \mathrm{ppm}$ ) seems to support a potential difference in the anabolic rate between LBW and control newborns.

One of the greatest differences is the free choline, with low levels in the LBW group. The spectral region between 4.06 and $4.08 \mathrm{ppm}$, belonging to fragments of phosphoethanolamine [42], also shows statistically significant differences in the LBW group. During gestation there is a high demand for this essential nutrient [43]. Choline, via its metabolite betain, serves as a donor of methyl groups for the production of S-adenosylmethionine (SAM), a substrate of DNA and histone methyltransferases [44]. DNA-methylation is catalyzed by DNA methyltransferases that transfer methyl groups from SAM to cytosine located in $\mathrm{CpG}$ dinucleotides. Different studies have shown that the prenatal choline supply affects the expression of multiple genes whose expression is regulated via epigenetic marks [45], [46]. Maternal choline supply during pregnancy modifies fetal histone and DNA methylation in rat fetal liver and brain [47]. Conversely, animals fed with diets deficient in choline and in methionine have altered global and gene-specific DNA and histone methylation [48]. These studies have demonstrated that maternal choline alterations during pregnancy modify fetal histone and DNA methylation, suggesting that a concerted epigenomic mechanism contributes to the long-term developmental effects of varied choline intake in utero.

Finding that the lower levels of choline are associated with LBW is compatible with the epigenetic programming hypothesis. Interactions of nutrients with the epigenetic machinery lead to changes associated with the regulation of gene expression that underlies the developmental programming consequences in adult life [49]. The epigenetic programming of the fetus in utero is under the influence of the altered metabolic milieu of pregnancy and the types of nutrients available through the maternal diet [50]. Alterations in nutrients, above all those related to DNA methylation, can modify the levels of DNA methylation and fetal programming [51]. Disease propensity in LBW children can be epigenetically programmed by intrauterine exposures that have the capacity to modify fetal genes through alterations in DNA methylation [52]. Deregulation of the epigenome may explain changes that are maintained throughout adult life. Indeed, lower levels of choline can explain the link between altered epigenetic regulation and environmental influence.

The differences found in choline, proline, alanine, glutamine, glucose, citrulline and phenylalanine at birth show that metabolic alterations are present in LBW. Even though it will be interesting and useful to clarify the mechanisms by which these metabolic changes lead to LBW consequences later in life, they are difficult to establish at present. Metabolic profile may be useful, however, in detecting differential phenotypes and in identifying 
those populations with the greatest potential risk. The identification of these differences can facilitate the search for alterations in tracking studies. These metabolites could be promising candidates in the search for the molecular differences capable of explaining the increased risk that LBW subjects exhibit for developing cardio-metabolic diseases later in life. That notwithstanding, whether or not these abnormalities are the source of low birth weight is difficult to establish.

Our findings suggest that a substantial component of metabolic disease risk has a prenatal developmental basis. Finding discriminatory metabolites in umbilical cord blood plasma from LBW newborns with a higher risk to develop cardio-metabolic disease may lead to their being used as potential biomarkers for the early prediction of risk and with the concomitant clinical implications for follow-up.

\section{Conclusions}

Both the presence of the differential metabolic profile, as well as the relationship of these metabolites with birth weight demonstrate that metabolic alterations are present and detectable at birth in LBW subjects. Beginning at birth, metabolic abnormalities provide information on the impact of intrauterine life. Whether these early disturbances in metabolism contribute to the development of cardio-metabolic diseases in these subjects later in life needs to be assessed in prospective studies.

\section{Additional file}

Additional file 1: Figure S1. Loadings plot of the PLS-DA model for discrimination between spectra of umbilical cord blood plasma from low vs normal weight babies at birth. Figure S2. Loadings plot of the PLS-DA model for discrimination between spectra of blood plasma from mothers of low vs normal weight babies at birth.

\section{Competing interests}

The authors declare that they have no competing interests.

\section{Acknowledgments}

This work was supported by the Instituto de Salud Carlos III (Spain) Grant 543 PI08/1277), By the Minsiterio de Ciencia e Innovacion off Spain (Grant SAF2011-23029), by the Conselleria de Sanidad (Comunitat Valenciana. Grant 544 GE010/15), and by CIBEROBN and CIBERDEM (both are initiatives of the 545 Instituto de Salud Carlos III). Cl is the recipient of a contract from the Sara 546 Borrell program (CD06/0111) and CIBEROBN. The authors would like to thank 547 Francisco Ponce Zanón, of the Laboratory of the Pediatric Cardiovascular Risk 548 Unit, Pediatric Department, for his technical assistance.

\section{Author details}

${ }^{1}$ Cardiovascular Risk Unit, Consorcio, Hospital General, University of Valencia, Av. Tres Cruces s/n, Valencia 46014, Spain. ${ }^{2}$ CIBER Fisiopatología Obesidad y Nutrición (CB06/03), Instituto de Salud Carlos III, Madrid, Spain. ${ }^{3}$ Unidad de Genotipado y Diagnóstico Genético, Fundación Investigación, Hospital Clínico Universitario de Valencia/INCLIVA Valencia, Av. Blasco Ibáñez, 17, Valencia 46010, Spain. ${ }^{4}$ CIBER de Diabetes y Enfermedades Metabólicas (CIBERDEM), Madrid, Spain. ${ }^{5}$ Fundación Investigación Hospital Clínico Universitario de Valencia / INCLIVA, Av. Blasco Ibáñez, 17, Valencia, Spain.
${ }^{6}$ Unidad Central Investigación Medicina, Universidad de Valencia /INCLIVA, Av. Blasco Ibáñez, 17, Valencia 46014, Spain. ${ }^{7}$ Department of Pediatrics, Consorcio Hospital General, University of Valencia, Av. Tres Cruces s/n, Valencia 46014, Spain.

\section{Authors' contributions}

$\mathrm{EL}$ and $\mathrm{Cl}$ conceived the study, designed it and wrote the manuscript. CGV informed the parents of the objectives of the research project, took the anthropometric measurements at birth and obtained the UCB samples. FJC participated in the experimental design and biochemical interpretations. DM and JMM performed the NMR measurements, NMR data analysis and biochemical interpretation of metabolomic data. All authors have read and approved the final manuscript.

Received: 3 April 2012 Accepted: 13 June 2012

Published: 9 July 2012

\section{References}

1. Barker DJ, Gluckman PD, Godfrey KM, Harding JE, Owens JA, Robinson JS: Fetal nutrition and cardiovascular disease in adult life. Lancet 1993, 341:938-941.

2. Burdge GC, Lillycrop KA: Nutrition, epigenetics, and developmental plasticity: implications for understanding human disease. Annu Rev Nutr 2010, 30:315-339.

3. Lubchenco Lo, Hansman C, Dressler M, Boyd E: Intrauterine growth as estimated from liveborn birth-weight data at 24 to 42 weeks of gestation. Pediatrics 1963, 32:793-800.

4. Godfrey KM, Barker DJ: Fetal nutrition and adult disease. Am J Clin Nutr 2000, 71(Suppl 5):1344S-1352S.

5. Hales CN, Ozanne SE: The dangerous road of catch-up growth. J Physiol 2003, 547(Pt 1):5-10.

6. Gluckman PD, Hanson MA, Cooper C, Thornburg KL: Effect of in utero and early-life conditions on adult health and disease. N Engl J Med 2008, 359:61-73.

7. Singhal A, Lucas A: Early origins of cardiovascular disease: is there a unifying hypothesis? Lancet 2004, 363:1642-1645.

8. Crispi F, Bijnens B, Figueras F, Bartrons J, Eixarch E, Le Noble F, Ahmed A, Gratacós E: Fetal growth restriction results in remodeled and less efficient hearts in children. Circulation 2010, 121:2427-2436.

9. Ligi I, Grandvuillemin I, Andres V, Dignat-George F, Simeoni U: Low birth weight infants and the developmental programming of hypertension: a focus on vascular factors. Semin Perinatol 2010, 34:188-192.

10. Lurbe E, Garcia-Vicent C, Torro I, Fayos JL, Aguilar F, de Llano JM, Fuertes G, Redón J: First-year blood pressure increase steepest in low birthweight newborns. J Hypertens 2007, 25:81-86.

11. de Martín Llano JJ, Fuertes G, Torró I, García Vicent C, Fayos JL, Lurbe E: Birth weight and characteristics of endothelial and smooth muscle cell cultures from human umbilical cord vessels. J Trans/ Med 2009, 7:30.

12. Kenny LC, Broadhurst DI, Dunn W, Brown M, North RA, McCowan L, Roberts C, Cooper GJ, Kell DB, Baker PN: Screening for Pregnancy Endpoints Consortium. Robust early pregnancy prediction of later preeclampsia using metabolomic biomarkers. Hypertension 2010, 56:741-749.

13. Suhre K, Meisinger C, Döring A, Altmaier E, Belcredi P, Gieger C, Chang D, Milburn MV, Gall WE, Weinberger KM, Mewes HW, Hrabé de Angelis M, Wichmann HE, Kronenberg F, AdamsKi J, LLLiq T: Metabolic footprint of diabetes: a multiplatform metabolomics study in an epidemiological setting. PLoS One 2010, 5:e13953.

14. Kim JY, Park JY, Kim OY, Ham BM, Kim HJ, Kwon DY, Jang Y, Lee JH: Metabolic profiling of plasma in overweight/obese and lean men using ultra performance liquid chromatography and Q-TOF mass spectrometry (UPLC-Q-TOF MS). J Proteome Res 2010, 9:4368-4375.

15. Mutch DM, Fuhrmann JC, Rein D, Wiemer JC, Bouillot JL, Piotou C, Clément $\mathrm{K}$ : Metabolite profiling identifies candidate markers reflecting the clinical adaptations associated with Roux-en-Y gastric bypass surgery. PLoS One 2009, 4:e7905.

16. Romero R, Mazaki-Tovi S, Vaisbuch E, Kusanovic JP, Chaiworapongsa T, Gomez R, Nien JK, Yoon BH, Mazor M, Luo J, Banks D, Ryals J, Beecher C: Metabolomics in premature labor: a novel approach to identify patients at risk for preterm delivery. J Matern Fetal Neonatal Med 2010, 23:1344-1359 
17. Sabatine MS, Liu E, Morrow DA, Heller E, McCarroll R, Wiegand R, Berriz GF, Roth FP, Gerszten RE: Metabolomic identification of novel biomarkers of myocardial ischemia. Circulation 2005, 112:3868-3875.

18. Brindle JT, Antti H, Holmes E, Tranter G, Nicholson JK, Bethell HW, Clarke S, Schofield PM, McKilligin E, Mosedale DE, Grainger DJ: Rapid and noninvasive diagnosis of the presence and severity of coronary heart disease using 1 H-NMR-based metabonomics. Nat Med 2002, 8:1439-1444.

19. Wang TJ, Larson MG, Vasan RS, Cheng S, Rhee EP, McCabe MC, Lewis GD, Fox CS, Jacques PF, Fernandez C, O'Donnell CJ, Carr SA, Mootha VK, Florez JC, Souza A, Melander O, Clish CB, Gerszten RE: Metabolite profiles and the risk of developing diabetes. Nat Med 2011, 17:448-453.

20. De Meyer T, Sinnaeve D, Van Gasse B, Tsiporkova E, Rietzschel ER, De Buyzere ML, Gillebert TC, Bekaert S, Martins JC, Van Criekinge W: NMRbased characterization of metabolic alterations in hypertension using an adaptive, intelligent binning algorithm. Anal Chem 2008, 80:3783-3790.

21. Ballard JL, Novak KK, Driver M: A simplified score for assessment of fetal maturation of newly born infants. J Pediatr 1979, 95:769-774.

22. Battaglia FC, Lubchenco LO: A practical classification of newborn infants by weight and gestational age. J Pediatr 1967, 71:159-163.

23. Nicholson JK, Foxall PJ, Spraul M, Farrant RD, Lindon JC: 750 MHz $1 \mathrm{H}$ and $1 \mathrm{H}-13 \mathrm{C}$ NMR spectroscopy of human blood plasma. Anal Chem 1995, 67:793-811.

24. Viant MR, Lyeth BG, Miller MG, Berman RF: An NMR metabolomic investigation of early metabolic disturbances following traumatic brain injury in a mammalian model. NMR Biomed 2005, 18:507-516.

25. Bertini I, Calabrò A, De Carli V, Luchinat C, Nepi S, Porfirio B, Renzi D, Saccenti E, Tenori L: The metabonomic signature of celiac disease. $J$ Proteome Res 2009, 8:170-177.

26. Trygg J, Holmes E, Lundstedt T: Chemometrics in metabonomics. J Proteome Res 2007, 6:469-479.

27. Cleal JK, Poore KR, Newman JP, Noakes DE, Hanson MA, Green LR: The effect of maternal undernutrition in early gestation on gestation length and fetal and postnatal growth in sheep. Pediatr Res 2007, 62:422-427.

28. Nissen PM, Nebel C, Oksbjerg N, Bertram HC: Metabolomics reveals relationship between plasma inositols and birth weight: possible markers for fetal programming of type 2 diabetes. J Biomed Biotechnol 2011, 2011:378268

29. García AP, Palou M, Sánchez J, Priego T, Palou A, Picó C: Moderate caloric restriction during gestation in rats alters adipose tissue sympathetic innervation and later adiposity in offspring. PLoS One 2011, 6:e17313.

30. He Q, Ren $P$, Kong $X, X u$ W, Tang $H$, Yin Y, Wang Y: Intrauterine growth restriction alters the metabonome of the serum and jejunum in piglets. Mol Biosyst 2011, 7:2147-2155.

31. Godfrey K, Robinson S, Barker DJ, Osmond C, Cox V: Maternal nutrition in early and late pregnancy in relation to placental and fetal growth. BMJ 1996, 312:410-414

32. Kwon H, Ford SP, Bazer FW, Spencer TE, Nathanielsz PW, Nijland MJ, Hess BW, Wu G: Maternal nutrient restriction reduces concentrations of amino acids and polyamines in ovine maternal and fetal plasma and fetal fluids. Biol Reprod 2004, 71:901-908.

33. Tamashiro KL, Moran TH: Perinatal environment and its influences on metabolic programming of offspring. Physiol Behav 2010, 100:560-566.

34. Cetin I, Ronzoni S, Marconi AM, Perugino G, Corbetta C, Battaglia FC, Pardi $\mathrm{G}$ : Maternal concentrations and fetal-maternal concentration differences of plasma amino acids in normal and intrauterine growth-restricted pregnancies. Am J Obstet Gynecol 1996, 174:1575-1583.

35. Cleal JK, Lewis RM: The mechanisms and regulation of placental amino acid transport to the human foetus. J Neuroendocrinol 2008, 20:419-426.

36. Jansson N, Pettersson J, Haafiz A, Ericsson A, Palmberg I, Tranberg M, Ganapathy V, Powell TL, Jansson T: Down-regulation of placental transport of amino acids precedes the development of intrauterine growth restriction in rats fed a low protein diet. J Physiol 2006, 576:935-946.

37. Bajoria R, Sooranna SR, Ward S, Hancock M: Placenta as a link between amino acids, insulin-IGF axis, and low birth weight: evidence from twin studies. J Clin Endocrinol Metab 2002, 87:308-315.

38. Huffman KM, Shah SH, Stevens RD, Bain JR, Muehlbauer M, Slentz CA, Tanner CJ, Kuchibhatla M, Houmard JA, Newgard CB, Kraus WE: Relationships between circulating metabolic intermediates and insulin action in overweight to obese, inactive men and women. Diabetes Care 2009, 32:1678-1683.
39. Newgard CB, An J, Bain JR, Muehlbauer MJ, Stevens RD, Lien LF, Haqq AM, Shah SH, Arlotto M, Slentz CA, Rochon J, Gallup D, Llkayeva O, Wenner BR, Yancy WS Jr, Heisenson H, Musante G, Surwit RS, Millington DS, Butler MD, Svetkey LP: A branched-chain amino acid-related metabolic signature that differentiates obese and lean humans and contributes to insulin resistance. Cell Metab 2009, 9:311-326.

40. Felig P, Marliss E, Cahill GF Jr: Plasma amino acid levels and insulin secretion in obesity. N Engl J Med 1969, 281:811-816.

41. Krebs M, Krssak M, Bernroider E, Anderwald C, Brehm A, Meyerspeer M, Nowotny P, Roth E, Waldhäusl W, Roden M: Mechanism of amino acid induced skeletal muscle insulin resistance in humans. Diabetes 2002, 51:599-605.

42. Monleón D, Morales JM, Gonzalez-Segura A, Gonzalez-Darder JM, Gil-Benso R, Cerdá-Nicolás M, López-Ginés C: Metabolic aggressiveness in benign meningiomas with chromosomal instabilities. Cancer Res 2010, 70:8426-8434

43. Zeisel $\mathrm{SH}$ : Choline: critical role during fetal development and dietary requirements in adults. Annu Rev Nutr 2006, 26:229-250.

44. Mehedint MG, Niculescu MD, Craciunescu CN, Zeisel SH: Choline deficiency alters global histone methylation and epigenetic marking at the Re1 site of the calbindin 1 gene. FASEB J 2010, 24:184-195.

45. Wolff GL, Kodell RL, Moore SR, Cooney CA: Maternal epigenetics and methyl supplements affect agouti gene expression in Avy/a mice. FASEB J 1998, 11:949-957.

46. Niculescu MD, Zeisel SH: Diet, methyl donors and DNA methylation: interactions between dietary folate, methionine and choline. J Nutr 2002, 132(Suppl 8):2333S-2335S.

47. Davison JM, Mellott TJ, Kovacheva VP, Blusztajn JK: Gestational choline supply regulates methylation of histone $\mathrm{H} 3$, expression of histone methyltransferases G9a (Kmt1c) and Suv39h1 (Kmt1a), and DNA methylation of their genes in rat fetal liver and brain. J Biol Chem 2009, 284:1982-1989.

48. Niculescu MD, Craciunescu CN, Zeisel SH: Dietary choline deficiency alters global and gene-specific DNA methylation in the developing hippocampus of mouse fetal brains. FASEB J 2006, 20:43-49.

49. Lillycrop KA, Slater-Jefferies JL, Hanson MA, Godfrey KM, Jackson AA, Burdge GC: Induction of altered epigenetic regulation of the hepatic glucocorticoid receptor in the offspring of rats fed a protein-restricted diet during pregnancy suggests that reduced DNA methyltransferase-1 expression is involved in impaired DNA methylation and changes in histone modifications. Br J Nutr 2007, 97:1064-1073.

50. Burdge GC, Hanson MA, Slater-Jefferies JL, Lillycrop KA: Epigenetic regulation of transcription: a mechanism for inducing variations in phenotype (fetal programming) by differences in nutrition during early life? Br J Nutr 2007, 97:1036-1046.

51. Thompson RF, Fazzari MJ, Niu H, Barzilai N, Simmons RA, Greally JM: Experimental intrauterine growth restriction induces alterations in DNA methylation and gene expression in pancreatic islets of rats. $J$ Biol Chem 2010, 285:15111-15118.

52. Einstein F, Thompson RF, Bhagat TD, Fazzari MJ, Verma A, Barzilai N, Greally JM: Cytosine methylation dysregulation in neonates following intrauterine growth restriction. PLoS One 2010, 5:e8887.

doi:10.1186/1479-5876-10-142

Cite this article as: Ivorra et al.: Metabolomic profiling in blood from umbilical cords of low birth weight newborns. Journal of Translational Medicine 2012 10:142. 